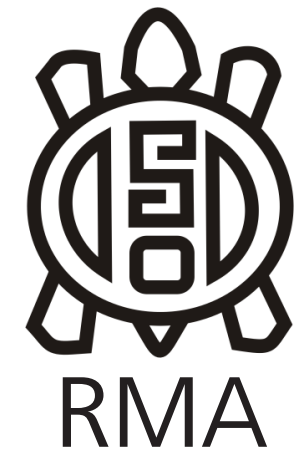

Dossier

\title{
Dos generaciones, un entierro: perspectivas osteobiográficas aplicadas al sitio Banda Meridional del Lago, Embalse de Río Tercero, Córdoba, Argentina
}

Two generations, one burial: osteobiographical perspectives applied to Banda Meridional del Lago site, Embalse de Río Tercero, Córdoba, Argentina

Paloma Zárate*, Claudina González**, Aldana Tavarone** y Mariana Fabra**

* Museo de Antropología (Facultad de Filosofía y Humanidades, Universidad Nacional de Córdoba). Av. Hipólito Yrigoyen 174, Córdoba, Argentina. Email: palomazrt@gmail.com

** Instituto de Antropología de Córdoba-IDACOR, Museo de Antropología (Facultad de Filosofía y Humanidades, Universidad Nacional de Córdoba). Av. Hipólito Yrigoyen 174, Córdoba, Argentina. Email: cvictoriagonzalez22@hotmail.com, aldyt@hotmail.com, marianafabra@gmail.com

\begin{abstract}
Resumen
El presente trabajo se orienta a reconstruir, desde una perspectiva osteobiográfica, la historia de vida de una mujer que habitó la región serrana de Córdoba durante el Holoceno tardío final, considerando dos grandes períodos dentro del curso de su vida, infancia y adultez. En particular, desde la bioarqueología social, interesa "humanizar el pasado", combinando la información bioarqueológica y arqueológica con un relato narrativo ficticio, forma alternativa a los principales géneros de escritura arqueológica y bioarqueológica. Los estudios osteobiográficos incluyeron la determinación del sexo, estimación de edad y lateralidad, el relevamiento de lesiones patológicas a nivel macroscópico y radiológico, así como cambios entesiales y degenerativos. Se incorporó información isotópica $\left(\delta^{13} \mathrm{C}, \delta^{15} \mathrm{~N}\right)$, arqueobotánica (silicofitolitos y almidones contenidos en tártaro dental) y genética (linaje mitocondrial) al estudio de caso. De esta forma se buscó ahondar, desde una perspectiva multidisciplinar, en una historia de vida singular moldeada por la dinámica sociocultural de una comunidad aldeana. Las experiencias corporizadas de esta mujer nos permiten indagar acerca de su salud, su alimentación, hábitos o usos del cuerpo. En particular, su entierro junto a un párvulo inhumado a sus pies en una urna, nos lleva a (re)pensar en las relaciones entre muertos, vivos y sus ancestros, desde una perspectiva relacional y superadora de los vínculos meramente biológicos.
\end{abstract}

Palabras clave: Bioarqueología social; Osteobiografía; Sierras de Córdoba; Holoceno tardío final.

\begin{abstract}
The aim of this article is to reconstruct, from an osteobiographical perspective, the life history of a woman who inhabited the mountainous region of Córdoba during the final late Holocene, considering two stages during her life, childhood and adulthood. From a social bioarchaeological perspective, it is interesting to "humanize the past", combining bioarcheological and archaeological information with a fictional narrative story, an alternative form to the main genre of archaeological and bioarcheological writing. We conducted osteobiographical studies, including the determination of sex, estimation of age and laterality, and detected macro- and microscopic pathological lesions, as well as entesial and degenerative changes. Isotopic $\left(\delta^{13} \mathrm{C}, \delta^{15} \mathrm{~N}\right)$, archaeobotany (silicophyitolites and starches contained in dental tartar) and genetics (mitochondrial lineage) information were incorporated into the case study. This study allowed us to explore a single unique life story, shaped by the sociocultural dynamics of a village community. The corporeal experiences of this woman concede us a way to comprehend her health, her diet, habits and uses of the body. In particular, her burial, together with an infant located at her feet in a ceramic vessel, leads us to (re)think the relationships between the dead, the living and their ancestors, from a relational perspective and overcoming merely biological associations.
\end{abstract}

Keywords: Social bioarchaeology; Osteobiography; Sierras of Córdoba; Final late Holocene. 
En los últimos años ha ido emergiendo una nueva perspectiva vinculada a la originada por Angel (1946), centrada en las osteobiografías humanas y en asociación a teorías que integran la bioarqueología social (Clark y Wilkie, 2006; Gilchrist, 2000; Stodder y Palkovich, 2007). Las mismas se basan en los presupuestos teóricometodológicos ofrecidos por el modelo biocultural (Blakely, 1977) y su innovación radica en su intento de "humanizar el pasado" y de entender al cuerpo humano como una construcción, producida por sus contextos de desarrollo biológicos y sociales (Agarwal, 2016). Esta perspectiva propicia una nueva mirada y permite pensar nuevas preguntas sobre las dimensiones culturales en las cuales los cuerpos biológicos se construyen y desenvuelven en vida. Asimismo, ayudan a la reconstrucción de las historias de vida e identidades sociales de los individuos bajo estudio, enriqueciendo las interpretaciones y la integración de los datos bioarqueológicos con información contextual cultural y social.

Así, el objetivo de este trabajo se orienta a reconstruir la historia de vida de una mujer que habitó la región serrana de Córdoba durante el Holoceno tardío final, considerando dos grandes períodos dentro del curso de su vida: infancia y adultez. Se siguió la propuesta de Gilchrist (2004) sobre curso de vida, entendido como un continuum de la experiencia de vida de un individuo, considerando las distintas etapas o estadios de manera concatenada, no aislada. Presentamos además una narrativa ficticia, siguiendo la propuesta de Boutin (2011), articulando datos arqueológicos, bioarqueológicos, clínicos y etnográficos con aportes ficticios, que permitan pensar, de forma breve y emotiva, en lo que pudieron haber sido los últimos momentos de la vida de esta mujer.

\section{El sitio arqueológico}

En el año 2005 fueron recuperados por arqueólogos del Área de Arqueología de la Dirección de Patrimonio Cultural de la Agencia Córdoba Cultura, un conjunto de restos óseos humanos conformado por un cráneo completo y restos de esqueleto postcraneal en buen estado de conservación, que habían sido expuestos de manera natural por la bajante del Embalse del rio Tercero, provincia de Córdoba (Fabra, 2006). El sitio se ubica en la costa sudeste de dicho embalse artificial, entre los ríos Grande y Quillinzo, frente a Villa Rumipal y la Usina Atómica de Embalse (Figura 1A, B, C). Se trata de un sitio al aire libre, definido a partir de un entierro primario doble de un individuo adulto y un párvulo. El individuo adulto se encontró en posición decúbito lateral derecho, con los miembros inferiores hiperflexionados sobre el tronco, ambos brazos cruzados entre las piernas y el tórax, y con una orientación del cráneo hacia el norte, los pies hacia el sur y las órbitas hacia el oeste (Fabra, Salega y González, 2009) (Figura 1D). Durante la exhumación se recuperó un párvulo dentro de una urna de cerámica (Figura 1E) ubicado a la altura de los pies, un hallazgo infrecuente para la región. En este sitio también se encontró otro enterratorio individual, material arqueológico lítico y cerámico y restos óseos faunísticos. Se desconoce el destino de sus restos como así también los del párvulo, mientras que los del individuo adulto que será analizado en este trabajo se encuentran en el Museo Arqueológico provincial Aníbal Montes, en Río Segundo, Córdoba. Si bien el infante no pudo analizarse, su hallazgo generó el interrogante sobre la contemporaneidad de sus muertes y la posibilidad de una relación filial o afectiva entre ambos.

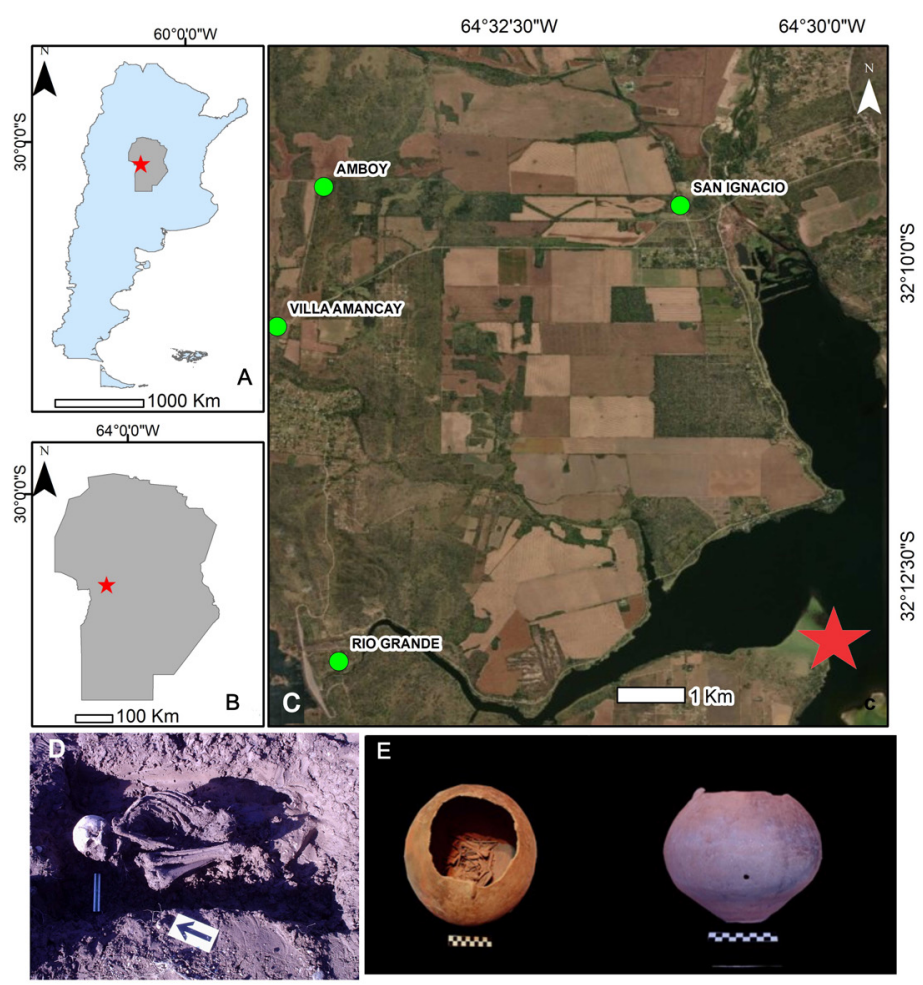

Figura 1. A, B, C) Ubicación geográfica del sitio arqueológico Banda Meridional del Lago, en el embalse de rio Tercero, provincia de Córdoba. La estrella roja indica la ubicación del entierro. D) Posición en la que fue hallado el esqueleto, decúbito lateral izquierdo con los miembros inferiores hiperflexionados sobre el tronco. E) Urna de cerámica que se encontraba a los pies de la mujer. En su interior, se pueden apreciar los restos óseos de un párvulo.

Figure 1. $A, B, C)$ Geographic location of Banda Meridional del Lago archaeological site, in Rio Tercero Reservoir, Córdoba province. The red star indicates the location of the burial. D) Position in which the skeleton was found, left lateral decubitus with the lower limbs hyperflexed on the trunk. E) Pottery found at the feet of the woman. Inside, you can observe the skeletal remains of an infant. 
Tabla 1. Perfil ostebiográfico del individuo.

Table 1. Osteobiographic profile of the individual.

\begin{tabular}{|c|c|}
\hline Nombre del sitio arqueológico & Banda Meridional del Lago (BML06). \\
\hline Preservación e integridad & $\begin{array}{l}\text { Restos óseos en buen estado de conservación. Se recuperaron la } \\
\text { gran mayoría de las partes esqueletales del individuo, a excepción } \\
\text { de ciertos huesos del esqueleto apendicular. }\end{array}$ \\
\hline Estimación de edad & Adulto de $46.8 \pm 7.8$ años al momento de su muerte. \\
\hline Determinación de sexo & Femenino. \\
\hline Fechado & $\begin{array}{l}695 \pm 20 \text { años AP (UCl AMS N N 39104, d13C, segundo } \\
\text { premolar superior derecho). }\end{array}$ \\
\hline Estatura & $1,61 \mathrm{mts}$. \\
\hline Lateralidad & Derecha. \\
\hline Patologías orales & $\begin{array}{l}\text { El estado de salud bucal es malo. Cuenta con un total de } 25 \\
\text { piezas dentales, a partir de las cuales se observaron tres PDAM, } \\
\text { dos caries, fracturas premortem, hipercementosis, labiación. } \\
\text { También presenta periodontitis y elevado desgaste dental (en } \\
\text { particular en dientes anteriores de la mandíbula). }\end{array}$ \\
\hline Modificaciones culturales & $\begin{array}{l}\text { Cráneo deformado con aplanamiento en frontal, parietales y en } \\
\text { occipital, más pronunciado del lado derecho. Surco oclusal en el } \\
\text { segundo premolar izquierdo. }\end{array}$ \\
\hline Lesiones premortem & $\begin{array}{l}\text { Hiperostosis porótica en parietales y occipital, de severidad leve } \\
\text { a media con evidencia de curación. Osificación completa del } \\
\text { cuerpo y manubrio del esternón junto con porosidad y procesos } \\
\text { líticos. Dos fracturas en vértebras, en la doceava torácica y } \\
\text { primera lumbar, con pérdida de altura. En diáfisis distal de la tibia } \\
\text { derecha, cara anterior, presenta pequeña reacción perióstica. } \\
\text { Fracturas en novena costilla. }\end{array}$ \\
\hline Marcadores degenerativos y entésicos & $\begin{array}{l}\text { Porosidad y osteofitos en vértebras, de mayor grado en la zona } \\
\text { baja de la columna. Deformación en vértebras torácicas y } \\
\text { lumbares. Osteofitosis en epífisis distal del fémur derecho. } \\
\text { Entesopatía en la línea poplitea de la tibia izquierda. Faceta de } \\
\text { Charles en epífisis distal del fémur izquierdo. Entesis en el } \\
\text { musculo subclavio en la clavícula derecha. }\end{array}$ \\
\hline Datos de isótopos estables & $\delta^{13} \mathrm{C}-16,3 \pm 0,5$ y $\delta^{15} \mathrm{~N} 9,0 \mathrm{col}$. \\
\hline Información arqueobotánica & $\begin{array}{l}301 \text { silicofitolitos y } 47 \text { granos de almidón contenidos en tártaro } \\
\text { dental. }\end{array}$ \\
\hline ADN mitocondrial & Haplogrupo C1. \\
\hline Análisis especializado & Radiografía de vértebras, sacro, costillas, esternón y cráneo. \\
\hline
\end{tabular}

también el ICSN 2011 (The International Code for Starch Nomenclature). A estos estudios se integraron datos contextuales del hallazgo y excavación arqueológica, información radiocarbónica así como isotópica $\left(\delta^{13} \mathrm{C}_{\mathrm{col}} \mathrm{y}\right.$ $\delta^{15} \mathrm{~N}$ ) y genética, a partir de análisis de ADN antiguo. La información es presentada en la Tabla 1.

\section{Osteobiografía}

Para la presentación del análisis bioarqueológico se considerarán dos etapas de la vida de esta mujer, su infancia y adultez. Las mismas no deberían ser entendidas como cortes diacrónicos sino momentos en la vida en que pudieron ocurrir los procesos patológicos observados y que se describirán a continuación.

Una de las propuestas críticas más interesantes de la bioarqueología social gira en torno a la edad, en la importancia de dar un paso más allá de las "edades cronológicas" medidas en días o años desde el nacimiento de la persona, y las "edades biológicas" estimadas a partir de evidencia física en los restos óseos, y comenzar a considerar la "edad social". Esta 
edad es planteada como categoría construida social y culturalmente (Knudson y Stojanowski, 2008; Sofaer, 2006). Su reconstrucción dependerá del contexto en que el individuo se desenvuelva, de cuánta información arqueológica, etnohistórica e histórica se disponga acerca de prácticas sociales y culturales de la población de la cual formó parte. En nuestro caso de estudio, la división de la historia de la mujer en etapas presentó ciertas dificultades, ante todo a la hora de distinguir entre las edades sociales y cuáles serían los criterios para su división. No se cuenta con información etnográfica sobre poblaciones de Córdoba que den cuenta de hechos, o prácticas sociales que pervivan en la memoria social de las comunidades actuales que nos permita pensar en edades socialmente construidas, así como las identidades sociales individuales y de pertenencia grupal en torno a ellas. Es por eso que los límites entre cada momento responden más bien a la edad cronológica, evitando perder las conexiones y continuidades entre ellos.

\section{Infancia}

La mujer que habitó Banda Meridional del Lago lo hizo entre 1271 y 1301 años de la era cristiana'. Compartió, con otros individuos de su comunidad, el linaje mitocondrial C1, variante nodal de amplia distribución en toda América, y particularmente de alta incidencia en poblaciones serranas y de las llanuras del centro de Argentina (Nores, Fabra y Demarchi, 2011). Poco tiempo después de haber nacido, hasta cumplidos los cinco años se le aplicaron fuerzas externas a su cráneo, deformándolo (O'Brien, Peters y Hines, 2013; Tiesler, 2012), y resultando en un aplanamiento de la zona frontal, los parietales y occipital (Figura 2A). A este tipo de deformación en la bibliografía se la denominó tabular oblicua intermedia (Dembo e Imbelloni, 1938).

Creemos que la deformación de su cráneo fue consecuencia de una práctica intencional cultural y no debida al uso de tablillas u otros artefactos para la carga o transporte de los recién nacidos e infantes (Munizaga, 1987; Ganot Rodríguez y Peschard Fernández, 1997). Es legítimo pensarlo si se tiene en consideración que en las sierras de Córdoba no se observa un patrón homogéneo de variantes de modificación de cráneos y que no todos los individuos la poseen. A nivel regional, la concepción de la deformación craneana como una práctica cultural compartida, presente en poblaciones cazadoras recolectoras desde al menos 4000 años AP, es presentada por varios autores que desarrollaron sus trabajos en Patagonia y en Pampa desde una perspectiva cultural, la cual supone la finalidad de estas marcaciones para diferenciación grupal (Berón y Baffi, 2003), desde una perspectiva evolutiva como marcadores étnicos que

\footnotetext{
${ }^{1}$ Se obtuvo un fechado radiocarbónico sobre colágeno dental de 695 \pm 20 años AP (UCl-39104, $\delta^{13} \mathrm{C}$, segundo premolar superior derecho). La calibración fue de 1210 cal. AD-1295 cal. D.C, con 2 sigmas/ probabilidad de un 95.4\%: con el programa OxCal v3.10, Bronk Ramsey (2005).
}

se generan y transmiten generacionalmente como parte de procesos de información cultural (Wiggenhauser, 2016). Una situación similar pudo estar relacionada con la deformación del cráneo de esta mujer, vinculada a una cuestión de identidad social e individual y de marcación del propio cuerpo. Seguramente fue un acontecimiento que integró a la recién nacida al grupo, reforzó su
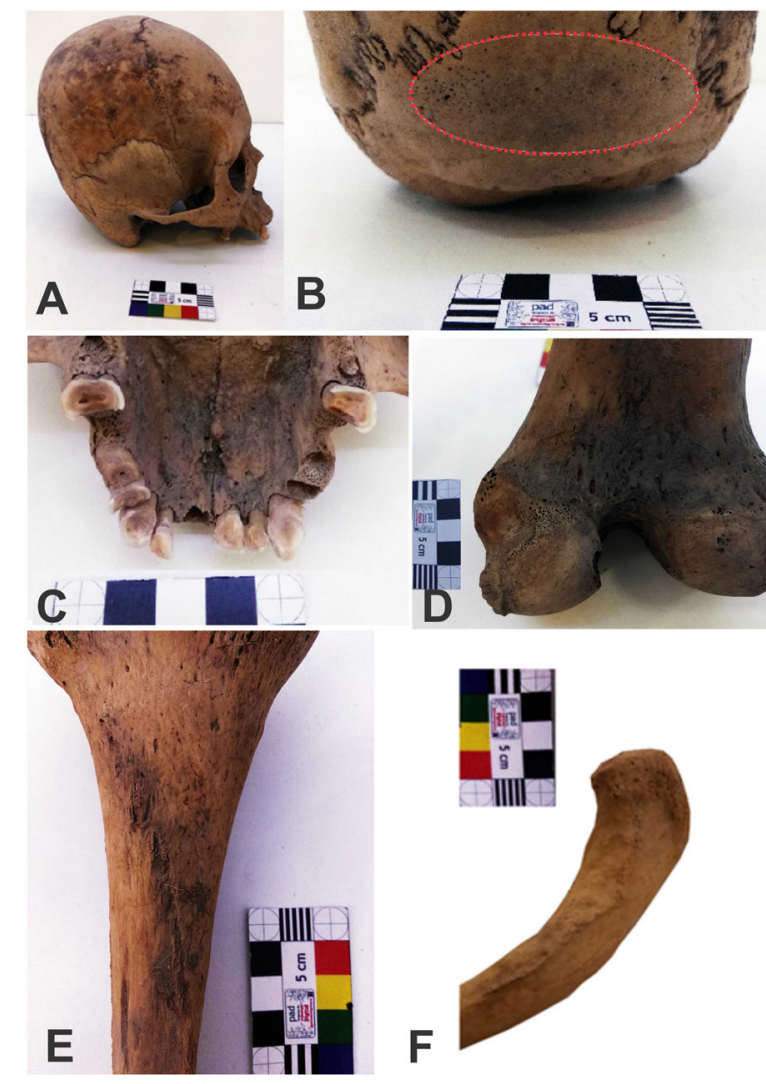

B

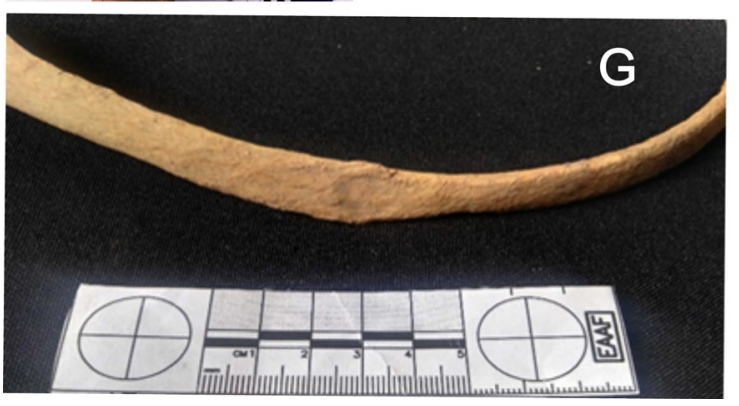

Figura 2. A) Vista lateral del cráneo donde se observa deformación. B) Hiperostósis porótica en occipital. C) Maxilar. Se observan microfracturas, PDAM, pérdidas dentales postmortem, un resto radicular y elevado desgaste dental. D) Faceta de Charles en cara posterior de epífisis distal del fémur izquierdo. E) Línea poplítea de la tibia derecha. F) Clavícula derecha con éntesis en el músculo subclavio.

Figure 2. A) Lateral view of the skull where deformation is observed. B) Porotic hyperostosis in the occipital bone. C) Jaw. Note microfractures, antemortem and postmortem tooth loss, a radicular rest and severe tooth wear. D) Posterior aspect of distal epiphysis of left femur showing Charles' facet. E) Popliteal line of the right tibia. F) Right clavicle with enthesis in the subclavian muscle. 
pertenencia y la diferenció con otros grupos humanos que cohabitaban en las sierras (Agarwal y Glencross, 2010; Torres-Rouff, 2002; Okumura, 2014).

De niña aparentemente también sufrió episodios de estrés producto de la anemia. Se observaron lesiones compatibles con hiperostosis porótica (Figura 2B), que suelen ser indicativas de esta patología (Aufderheide y Rodríguez-Martín, 1998; Ortner, 2003). Estudios han demostrado que son los niños los afectados en mayor medida por los factores que contribuyen al desarrollo de la misma, por lo que se sostiene que las lesiones que se observan en restos óseos de individuos adultos son el resultado de cambios que ocurren en el período de crecimiento y que no han sufrido remodelación ósea (Stuart-Macadam, 1985). En cuanto a gravedad y temporalidad podríamos decir que se trató de una anemia crónica no tan severa y que presenta signos de cicatrización.

La anemia no es una enfermedad en sí, sino que remite a diversas causas socioculturales, nutricionales y medioambientales (Larsen, 1987) entre las cuales se encuentran una dieta inadecuada, una absorción deficiente o una mayor utilización de hierro, pérdida de sangre o una infección (Stuart-Macadam, 1989; Suby, 2014). En este caso, las causas probables pudieron haber sido resultado de diversos escenarios, desde una ingesta abundante de frutos o vegetales tanto recolectados como cultivados en comparación con el consumo de alimentos fuentes de proteína como lo son los animales, o una inadecuada absorción del hierro determinada por componentes dietéticos que la inhiben como por ejemplo, fosfatos, calcio y niveles bajos de vitamina C (Hallberg y Hulthén, 2000 en Suby, 2014). Si bien no observamos lesiones óseas compatibles con procesos infecciosos, no descartamos completamente como causas explicativas entre otras para el caso de la anemia.

A pesar de que haber sufrido un episodio de estrés producto de un disturbio metabólico, este no repercutió en su normal crecimiento. Su altura promedio de 1,61 m se encuentra dentro de la media observada para mujeres que habitaron las sierras de Córdoba en momentos finales del Holoceno tardío (Loupias y Fabra, 2019).

Es muy posible que su ayuda en tareas cotidianas como recolección y procesamiento de plantas y animales o manufactura de distintos tipos de objetos o artefactos desde su niñez, fuera aumentando su intensidad a través de los años. Tal como lo presenta Gilschrist (2004), se ha tendido a caracterizar a la infancia como un período de dependencia prolongado y a costas de los adultos, pero los estudios arqueológicos demuestran que los infantes mantuvieron roles activos dentro de la economía.

\section{Adultez}

La alimentación de esta mujer fue variada. Los análisis

\begin{tabular}{|l|ll|ll|}
\hline Familia & Género/Especie & Estatus & SF & GA \\
\hline Solanaceae & Solanum tuberosum & domesticado & 0 & 2 \\
Cucurbitacea & Cucurbita sp. & domesticado & 2 & 0 \\
Poaceae & Zea mays & domesticado & 1 & 13 \\
Fabaceae & Prosopis sp. & silvestre & 16 & 27 \\
Aracaceae & Trithrinax campestris & silvestre & 21 & 0 \\
Fabaceae & Geoffroea decorticans & silvestre & 9 & 0 \\
& Poaceas & silvestre & 215 & 0 \\
& sin identificar & & 37 & 5 \\
\hline
\end{tabular}

Tabla 2. Fitolitos de sílice y granos de almidón hallados en el cálculo dental. Referencias. SF: silicofitolitos, GA: granos de almidón.

Table 2. Silicophyitolites and starches found in dental tartar. References: SF: Silicophytolites, GA: starch grains.

arqueobotánicos permitieron documentar la presencia de 301 silicofitolitos y 47 granos de almidón. Entre los silicofitolitos más abundantes encontramos las formas en cono truncado y prismáticos. A su vez, se identificaron formas bilobadas, rectangulares, buliformes y oblongas. Entre los granos de almidón se registró principalmente la presencia de formas circulares $(\mathrm{N}=23)$, seguidas por morfotipos poligonales $(\mathrm{N}=15)$ y ovales $(\mathrm{N}=9)$.

En relación a las afinidades botánicas, se observaron principalmente morfotipos relacionados con la familia de las poáceas ( $\mathrm{N}=215)$. A su vez se observaron silicofitolitos de forma circular de color rosado o amarillento y granos de almidón también circulares de contorno tanto regular como irregular, los cuales según Korstanje y Babot (2007) pueden ser asociados a los frutos comestibles del género Prosopis (Fabaceae)"algarrobo" ( $\mathrm{N}=16)$. Por otro lado, los elementos poliédricos de textura plana e incolora fueron semejantes a los descriptos por Korstanje y Babot (2007) y Medina, López y Berberián (2009) para el "chañar" Geoffroea decorticans (Fabaceae) $(\mathrm{N}=9)$. Por último, se encontraron abundantes silicofitolitos globulares de ápices romos, similares a los descriptos para la familia de las Aracáceas $(\mathrm{N}=21)$, los mismos fueron asociados particularmente a la especie Trithrinax campestris "Palma Caranday" (Benvenuto, Honaine, Osterrieth y Morel, 2015).

Con respecto a las plantas posiblemente cultivadas, se identificaron elementos silíceos y almidonosos cuyos atributos morfológicos fueron asociados a la especie Zea mays "maíz". A su vez, se hallaron 2 granos de almidón de forma oval que permitieron identificar la especie Solanum tuberosum "papa" en una de las muestras analizadas (Korstanje y Babot, 2007), además, la presencia de dos fitolitos esféricos con concavidades continuas logró la identificación de la familia de las Cucurbitaceas en este individuo (Bozarth, 1987; Medina et al., 2009; Piperno, 2006).

Pudo consumir los frutos del algarrobo, mistol, el chañar y la palma de manera directa o procesados como bebidas refrescantes (conocida como añapa), alcohólicas (aloja) 
y dulces (arrope) y también a través de harinas refinadas (Arias Toledo, Colantonio y Galetto, 2007; Capparelli y Lema, 2011; Figueroa y Dantas, 2006; López, 2015; Medina y Pastor, 2006). Los microrestos analizados presentaron evidencia de daño consistente con la exposición al calor, la manipulación y el procesamiento de las distintas partes de la planta, como lo demuestran alteraciones tales como grietas, distorsión, superficies quebradas, cruz de extinción expandida e hinchazón general en 32 de los granos de almidón encontrados (Babot, 2003; Henry y Piperno, 2008; Henry et al., 2009).

También consumió maíz pero sin una incidencia destacada en su dieta. Si evaluamos los valores isotópicos de carbono 13 sobre colágeno ${ }^{2}\left(\delta^{13} C_{c o l}\right),-16,3 \% \pm 0,5$, nos permite suponer que consumió tanto vegetales de fotosíntesis C3, C4 o CAM, silvestres y cultivados (Coltrain y Leavitt, 2002; Fabra y González, 2019; Gil, Tykot, Neme y Shelnut, 2006; Pate, 1994).

Sumadas a la información arqueológica, arqueobotánica e isotópica, las patologías orales que presenta esta mujer también nos permiten examinar su alimentación. Además de un desgaste dental muy severo, sufrió de patologías infecciosas y degenerativas tales como numerosas pérdidas dentales antemortem, caries, hipercementosis, labiación y fracturas premortem (Figura 2C). Todas ellas estarían indicando el uso intensivo del aparato masticatorio, posiblemente relacionado con la textura de los alimentos y las formas en que fueron preparados (Gómez Otero y Novellino, 2011). En algún momento de su vida contrajo enfermedad periodontal, no se podría saber con exactitud en qué momento pero seguramente haya progresado con el paso del tiempo, agravándose en su etapa adulta.

Su dentadura es muy particular por otro rasgo: el patrón característico del desgaste dental. En los dientes anteriores de la mandíbula, el desgaste no es el típico producido por presiones masticatorias derivadas del consumo de alimentos, y posee un surco en el segundo premolar izquierdo que estaría indicando algún tipo de acción frecuente que lo haya modificado de tal modo. Se sugiere el uso de su dentadura como una "tercera mano" o herramienta en tareas como pudieron ser la confección y decoración de vasijas, cestas y torteros las cuales requerían tirar, ajustar y cortar los distintos tipos de fibras que se utilizaban. Varios autores (Baker Terhune y Papalexandrou, 2012; Molnar, 1971) observaron que los desgastes inusuales se presentan con mayor preponderancia en mujeres. En otras poblaciones cazadoras recolectoras, por ejemplo, del centro-sur de nuestro país (Flensborg, 2011; Luna y Aranda, 2014), también se observa una mayor presión masticatoria en individuos femeninos que podría estar relacionada a la utilización de la dentición en actividades cotidianas

\footnotetext{
2 Dicho valor fue el obtenido por la realización del fechado radiocarbónico ${ }^{14} \mathrm{C}$ a partir del colágeno dental.
}

como la preparación de alimentos o la elaboración de utensilios. En las Ilanuras de Córdoba, González y Fabra (2018) también notan la incidencia de formas oblicuas en la dentición anterior de individuos femeninos las cuales la

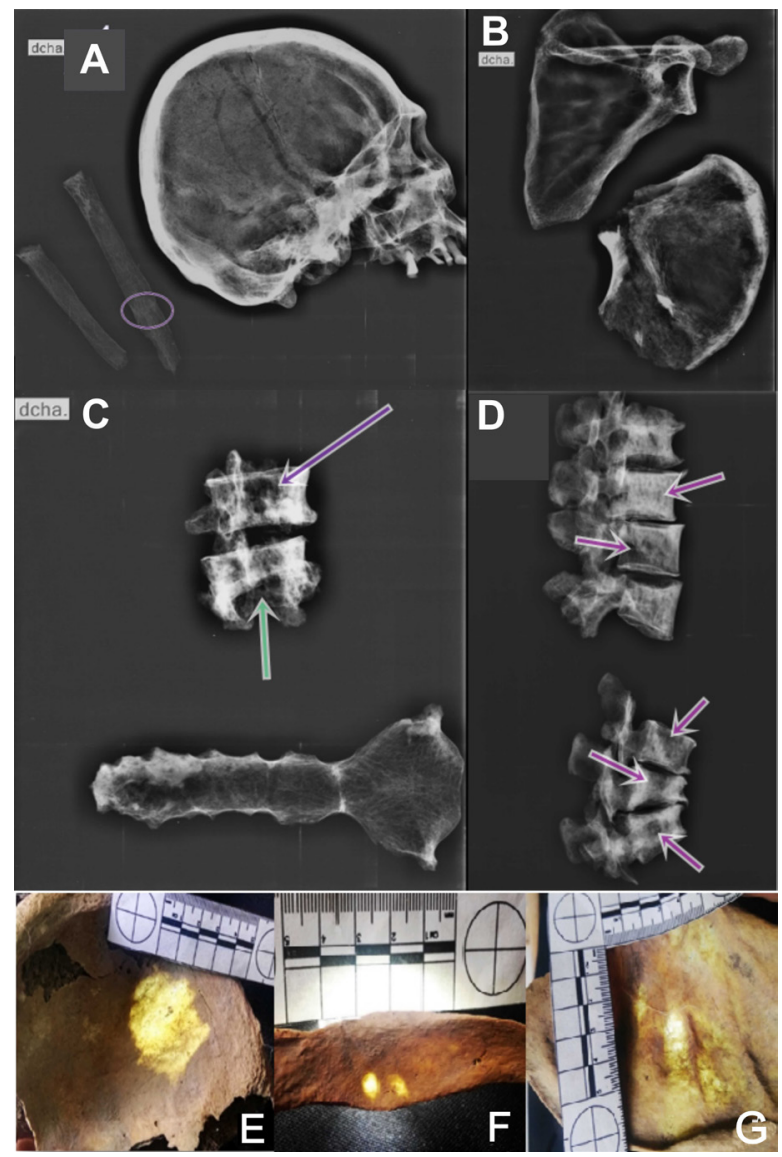

Figura 3. A, B, C, D) Radiografías tomadas a huesos con lesiones/patologías a nivel macroscópico. 3A) Costillas $n^{\circ} 9$ y 10. En la novena se observa una fractura premortem totalmente osificada. En cráneo no se observa ninguna patología. 3B) Escápula y pelvis. 3C) Sacro, sin ninguna evidencia de patologías. Vértebra torácicas $n^{\circ} 11$ y 12 . En la $n^{\circ} 11$ se observa pérdida de densidad ósea mientras que en la $n^{\circ} 12$ se evidencia fractura premortem y pérdida de tejido óseo por daños tafonónicos. 3D) Arriba: vértebras lumbares $n^{\circ} 2$ a 5 . La 3 y 4 tienen pérdida de densidad ósea en cuerpo vertebral. Abajo: vértebras torácicas $n^{\circ} 11$ y 12 y lumbar $n^{\circ} 1$. La única que presenta pérdida de densidad ósea es la vértebra torácica $\left.n^{\circ} 11.3 F, G, H\right)$ Radiopacidad en ilion, costilla y omóplato.

Figure 3. $A, B, C, D) X$-rays taken of bones with lesions/ pathologies at macroscopic level. 3A) Ninth and tenth ribs. In the ninth rib, a fully ossified premortem fracture is observed. No pathology is observed in the skull. B) Scapula and pelvis. 3C) Sacrum, without evidence of pathology. Eleventh and twelfth thoracic vertebrae. In the eleventh vertebra, bone loss is observed, while in twelfth, there is evidence of a premortem fracture and loss of bone tissue due to taphonomic damage. 3D) Above: second to fifth lumbar vertebrae. The third and fourth have loss of bone density in vertebral body. Bottom: eleventh and twelfth thoracic vertebrae and first lumbar vertebra. The only one with loss of bone density is the eleventh thoracic vertebra. 3F, G, H) Radiopacity in ilium, rib and scapula. 
relacionan con actividades de este tipo. De esta manera, el uso del cuerpo estaría reflejando un tipo de actividad realizada por las mujeres particularmente, asociada a la manufactura de distintos objetos y materiales haciendo uso de la boca y los dientes como herramienta.

Observamos indicadores en su esqueleto, que además de estar relacionados con la edad como factor desencadenante de procesos degenerativos del tejido cartilaginoso y de producción de tejido óseo, pueden interpretarse como posibles indicadores de actividad. Esta actividad debió requerir esfuerzo físico repetido, más o menos intenso, a lo largo de su vida. En la cara posterior de la epífisis distal del fémur izquierdo se observó la faceta de Charles (Figura 2D), en la parte superior del cóndilo medial sobre el tubérculo aductor en el área de unión del músculo gastrocnemio. Se trata de una faceta accesoria, denominada así por el primer autor en describirla (Charles 1893). Se presenta como una zona lisa, regular y sin foramen. Esta variación anatómica ha sido considerada como una extensión de la superficie articular del cóndilo medial o bien el origen individualizado del músculo gastrocnemio medial (Villote y Prada Marcos, 2010). Se registró entesopatía en la línea poplítea de la tibia derecha (Figura 2E), tanto defecto como crecimiento óseo y elevación de la línea poplítea, en el lugar de inserción de los músculos sóleo y poplíteo (Estévez González, 2002). En cuanto a marcadores ocupacionales, se observó un cambio entesial en la clavícula derecha en la inserción del musculo subescapular (Figura 2F). Este músculo surge de la superficie inferior de la escápula e inserciones en el tubérculo menor del húmero y su función es ayudar a rotar el brazo hacia adentro y su aducción al cuerpo (Cantarella, 1999). El conjunto de estos marcadores sugieren desplazamientos diarios, un mayor uso del brazo derecho y posiblemente la adopción de la postura en cuclillas y la habitual hiperflexión de la rodilla. Sumado a esto, puede que haya trasportado cargas pesadas sobre su espalda ya que el manubrio y esternón se encuentran fusionados. Su causa es la destrucción de la articulación manubrio-gladiolar resultado de la aplicación de una fuerza vertical sobre el cuerpo (Capasso, 1999).

Un evento traumático también aconteció en su vida: se observó una lesión en su novena costilla derecha, definida como una fractura simple y transversal (Figura 2G). Una vez producida la lesión sobrevivió el tiempo suficiente para que el tejido óseo se regenerara, lo cual permite situar la ocurrencia del suceso en meses o años antes de su muerte. Las suposiciones en cuanto a la causa de dicho evento la relacionan a una caída, probablemente debido a la movilidad reducida luego de las dos fracturas que sufrió en las vértebras.

Además, fue llamativa la radiopacidad observada en ciertos huesos al exponerlos a contraluz (Figura 3E, F, $\mathrm{G})$. En el caso de los omóplatos es bilateral, en el ilion del lado derecho y la costilla afectada fue la doceava izquierda. Esta anomalía junto a una serie de lesiones en el esqueleto axial y apendicular nos llevaron a considerar un panorama más general a nivel patológico y a realizar radiografías de todos los huesos afectados (Figura $3 \mathrm{~A}, \mathrm{~B}$, $C, D)$, las cuales fueron útiles al momento de realizar un diagnóstico diferencial entre enfermedades que podrían haber producido morfológicamente respuestas óseas similares.

La zona más afectada fue la parte baja de su columna vertebral la cual presenta fracturas en la doceava vértebra torácica y primera vértebra lumbar con una consecuente cifosis. Se observó además deformación de las carillas articulares en vértebras torácicas y lumbares, osteofitosis y porosidad en todas las vértebras (de leve a grave). En cuanto a la porosidad en las cervicales, es el lado derecho el que está más afectado ya que se encuentra presente en grado medio en las facetas articulares derechas. En las torácicas comienzan a estar afectadas ambas facetas articulares como así también el cuerpo. Estos últimos se encuentran destruidos, con ausencia de tejido.

En segundo lugar, fueron las escápulas, esternón y sacro los huesos que presentaron lesiones caracterizadas por pequeños agujeros o macroporosidad de bordes alisados. Muchas de estas lesiones osteolíticas destruyeron el hueso trabecular, y en algunas ocasiones la porosidad tuvo una extensión y tamaño tal que podría ser considerada signo de procesos líticos. No se observó hueso reactivo asociado a las lesiones o a su alrededor, únicamente una reacción perióstica localizada en la diáfisis distal anterior de su tibia derecha.

Para el diagnóstico diferencial se incluyeron enfermedades infecciosas como la tuberculosis, la osteomielitis y la brucelosis, infecciones micóticas (fúngicas), mieloma múltiple y osteoporosis. En la Figura 4 se presenta un resumen de las lesiones detectadas, el grado de severidad y las enfermedades a las cuales podrían corresponderse.

Varias de estas enfermedades producen a la vez que lesiones líticas, lesiones osteoblásticas en diferente grado y características. Dentro de las infecciosas, la osteomielitis produce formación de hueso nuevo alrededor de la zona infectada del hueso (involucro) y suele ser patognómica la presencia de una cloaca, pero ninguno de los dos rasgos fue observado en el análisis macroscópico o radiográfico. La brucelosis era poco factible por el hecho de que su propagación entre humanos es muy rara (Glasgow, 1976, p. 283) y su presencia depende de animales domésticos, introducidos en América con posterioridad al contacto hispano indígena. No se conocen casos anteriores a la introducción por parte de poblaciones europeas de ganado y animales domésticos (Guraieb, 2010). Tampoco se notó neoformación, que es la tendencia en el segundo momento de la enfermedad. Lo mismo sucedió con la infección micótica, los huesos no presentan la característica formación perióstica circunferencial 

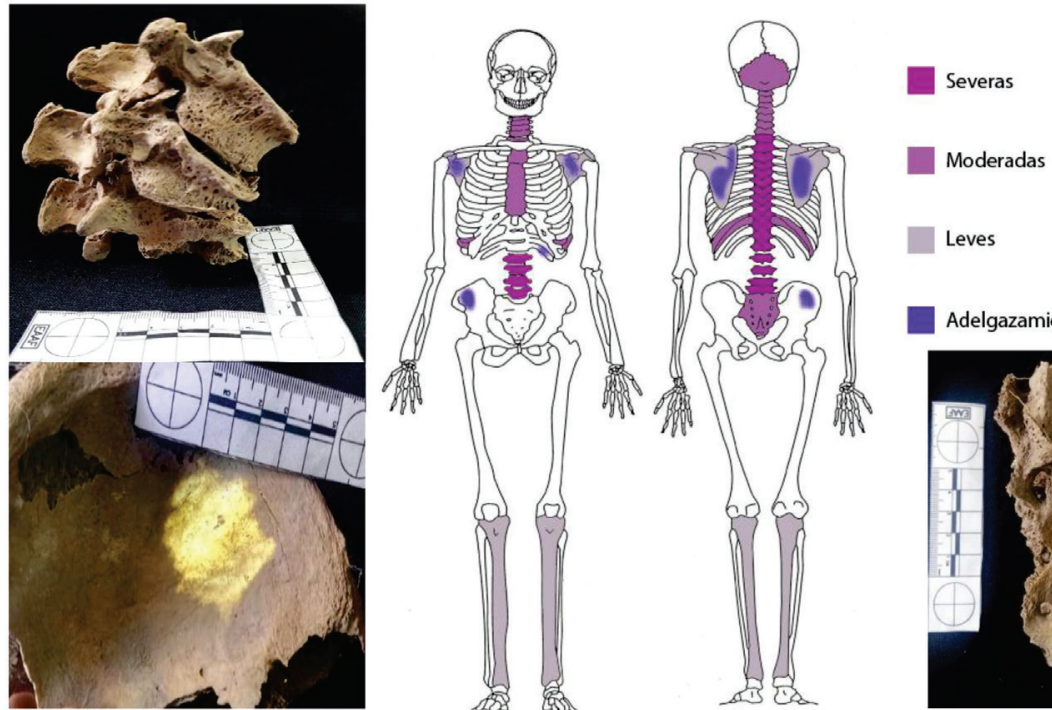

Leves
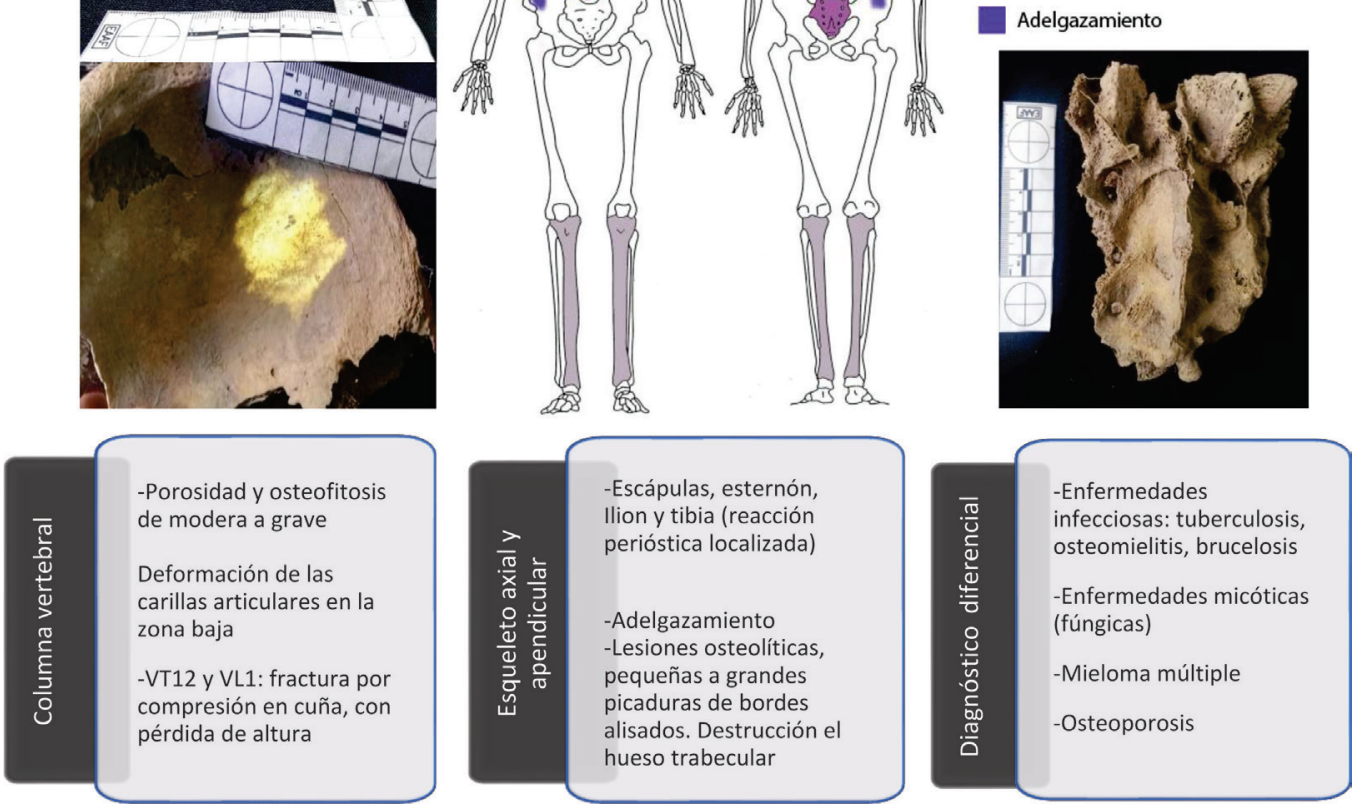

Figura 4. Elementos óseos afectados por lesiones y condiciones patológicas en el esqueleto de la mujer, grado de severidad y enfermedades a las cuales podrían corresponderse.

Figure 4. Bone elements affected by injuries and pathological conditions in the female skeleton, degree of severity and diseases to which they could correspond.

alrededor de los márgenes de las lesiones.

En el caso de la tuberculosis, el patrón de las lesiones -no estaban afectadas las costillas en su aspecto visceral que son un rasgo clave asociado a esta enfermedad, ni dedos ni manos- al igual que la falta de procesos blásticos en los huesos, puso en duda que pudiera tratarse de esa enfermedad (Aufderheide y Rodríguez-Martín, 1998; Ortner, 2003). Las lesiones líticas y su localización junto con la cifosis que observamos macroscópicamente en las vértebras eran similares a las que se producen en casos de esta infección. Sin embargo, las radiografías no mostraron signos de lesiones patológicas que puedan atribuírsele (Figura 3C y D).

Descartadas las anteriores patologías quedan las dos afecciones que se consideraron como potenciales diagnósticos: el mieloma múltiple y la osteoporosis. En el caso de la condición neoplásica coincide la descripción de la presencia de lesiones destructivas difusamente distribuidas que comienzan en el hueso esponjoso y las fracturas en costillas. También era coincidente con la edad, ya que raramente ocurre antes de los cuarenta años (Ortner, 2003), a pesar de que tiene mayor incidencia en individuos masculinos. Pero nuevamente, las radiografías no mostraron signos de lesiones patológicas coincidentes.

En síntesis, según la apariencia y distribución de las lesiones la avanzada edad y el sexo, las consideramos compatibles con osteoporosis. Las radiografías refuerzan esta hipótesis ya que se observa claramente la pérdida de densidad ósea en vértebras torácicas y lumbares. Esta pérdida ósea fue la responsable del colapso de las vértebras, dado que la mayor pérdida se dio al centro de los cuerpos vertebrales y contribuyó a su fragilidad. La pérdida ósea en la columna vertebral ocurre progresivamente y se caracteriza por cambios en la radiolucidez del hueso, en el patrón trabecular y en la forma de los cuerpos vertebrales (González-Reimers et al., 2004).

Esta condición tiene un origen multi-factorial, en el cual pueden estar implicados aspectos de la homeostasis mineral y las concentraciones de vitamina D (la ingesta de calcio y concentración de vitamina $\mathrm{D}$ tienden a disminuir con la edad); la disminución en la función ovárica anterior al período menopáusico; el estrés reproductivo y lactancia materna; el nivel de masa ósea máxima que refiere 
al tejido óseo que se acumula al final del crecimiento durante la adolescencia y antes del inicio de la pérdida ósea relacionada con la edad (Brickley e Ives, 2008). En este último interactúan diversas circunstancias que guardan relación con el contexto de crecimiento tales como la salud a lo largo del mismo, factores ambientales, la nutrición, el grado de actividad física realizada, factores fisiológicos y genéticos, entre otros.

Para la región patagónica, Suby y colaboradores (2012) observan una reducción de la densidad de masa ósea mayor al 25\% en mujeres a partir de los 30 años, y lo relacionan a la maternidad y a deficiencias nutricionales. Se cree que ambas causas podrían haber estado afectando el metabolismo de la mujer de Banda Meridional del Lago.

De este modo, vemos que con el paso de los años las huellas que se evidencian en el cuerpo de la mujer, y en sus huesos, son numerosas. Afecciones en su boca, un trauma por fractura en su novena costilla derecha y su espalda muy comprometida hicieron que su movilidad y desempeño físico no fuera nada fácil. En personas que padecen de osteoporosis, las caídas y golpes, al igual que actividades diarias que impliquen soportar pesos en posición vertical, toser, reír y saltar pueden aumentar las cargas compresivas vertebrales y resultar en fracturas vertebrales (Riggs y Melton, 1988). Seguramente este fue el caso de esta mujer. Con respecto a si sufrió o no, la osteoporosis es generalmente una condición asintomática hasta que se produce una fractura (Moyad, 2003).

\section{Nadie nace solo, nadie muere solo. Cómo la vida y la muerte son elementos de un ciclo, en un mismo espacio.}

Al inicio de la de la excavación de los restos óseos, los arqueólogos no notaron nada peculiar: parecía una inhumación habitual de los grupos que habitaban la región. Sin embargo, al avanzar con la exhumación, detectaron algo a los pies de la mujer. Se trataba de una vasija de cerámica, conteniendo en su interior restos óseos que posteriormente definieron correspondía a un párvulo (Alfonso Uribe, com.pers.) (Figura 1E). Son muy escasos los hallazgos de subadultos en el territorio cordobés, su visibilidad en el registro arqueológico es casi nula y que el párvulo haya estado en una urna, es un hallazgo infrecuente.

Por las características del entierro, y el material recuperado ${ }^{3}$ consideramos que pudo tratarse de un contexto residencial tal como varios de los sitios que

\footnotetext{
${ }^{3}$ Se recuperaron materiales arqueológicos que pueden ser asociados al individuo, y cuya tecnología permite suponer que corresponden a un contexto agroalfarero: 12 fragmentos de cerámica; un conjunto de desechos e instrumentos líticos compuestos por tres lascas de cuarzo y una de cuarcita marrón, dos fragmentos de núcleo, un cuchillo de filo natural y una muesca retocada; material óseo faunístico correspondiente a falanges, fragmentos de huesos largos y un fragmento de cáscara de huevo de ñandú (Fabra, 2006).
}

se encuentran para momentos tardíos en la región. El entierro dentro de los lugares de residencia, donde pasaban gran parte del día haciendo distintas actividades, desde dormir, cocinar y comer, ocio, artesanías, criar a los niños, pudo implicar una intencionalidad manifiesta -y con algún tipo de significado- de inscribirlos en el ámbito doméstico (Larrain, Spano y Grimoldi, 2017). El uso del espacio como vivienda y como lugar funerario fue simultáneo (Laguens y Bonnin, 2009; Pastor y Berberián, 2007). Las casas fueron lugares donde coexistieron los distintos elementos de un ciclo, la vida, la muerte y la reproducción. Vemos, además, cómo se integró la materialidad cotidiana mediante el uso de una vasija de cerámica en el rito funerario asociado al infante.

El entierro de un ser querido o un miembro de la comunidad es un acto imbuido de significado (Murphy y Le Roy, 2017). Cuando consideramos no sólo la práctica en sí sino el contexto mortuorio, vemos que este tiene como componente constitutivo lo cultural, nos brinda información sobre la persona que murió (cómo y dónde murió, en qué momento de su vida) al mismo tiempo que permite la comprensión de la forma de actuar y pensar de los vivos que la enterraron. El ritual implicado en una inhumación tiene más relación con las personas que lo realizan y dice más de ellos que del muerto. Puede revelar cómo la sociedad ve al individuo después de la muerte, examinando por ejemplo ofrendas y veneración de antepasados, e incluso cómo los cuerpos sin vida siguen teniendo agencia dentro de la sociedad (Martin, Harrod, Ventura y Pérez, 2013).

Los rituales funerarios hacen a la trascendencia de un grupo, operan en el presente y el pasado. Pasado, porque entrelazan tiempos y generaciones a través de memorias que son revividas en estos actos; presente, porque operan en la vida política y social cotidiana de la comunidad (Larrain et al., 2017), en la cohesión y refuerzos de lazos comunales y de familia (Douglas, 1996; Laneri, 2007).

El primer interrogante que surgió a la hora de pensar en el entierro de la mujer y el infante de Banda Meridional del Lago fue la posibilidad de que existiera una relación de parentesco, de madre-hijo, abuela-nieto o bien afectiva. Presumiblemente podrían ser madre-hijo si se consideran algunos antecedentes sobre entierros de personas con vínculo biológico. Como caso, se puede mencionar el entierro doble de un padre y un hijo en la costa sur de la Laguna Mar Chiquita, fechado en $750 \pm 50$ años ${ }^{14} \mathrm{C}$ AP. Las características del entierro y el material asociado a los individuos llevaron a realizar análisis genéticos para comprobar si existía, como se suponía, un vínculo filial entre el adulto y el niño (Nores, Fabra, Rena, Modesti y Demarchi, 2014) dando los mismos positivo. También existen casos en la Quebrada de Humahuaca, demostrados a través del estudio de ADN antiguo, de parentesco entre individuos enterrados en las mismas tumbas (Russo, Mendisco, Avena, Dejean y Seldes, 
2016). Los resultados positivos apoyan la suposición de que el entierro doméstico de personas relacionadas fue una práctica extendida a lo largo del tiempo en distintas regiones.

La posibilidad de que haya un parentesco biológico aún no ha sido comprobada, pero de lo que no hay dudas es que tuvieron alguna relación, sea familiar o afectiva. En este punto fue revelador la contribución de Johnston (2019), quien problematiza la manera en que se trabajó el parentesco en nuestra disciplina y hace visible la importancia de plantear otras formas de parentesco y organización familiar, más amplias, que excedan la visión genealógica y heteronormativa de la familiar nuclear, con las limitaciones que implica. En su argumento expone que los datos aportados por la genética o por análisis moleculares brindarán información (más certera) de un aspecto de la relación biológica, pero se escapará de su interpretación una parte importante de la misma, la de las relaciones sociales, membresía y pertenencia de las personas con respecto a un grupo familiar (Johnston, 2019).

¿Qué implicancias y/o significados sociales se desprenden de esta práctica funeraria? El hecho de que la mujer y el infante hayan sido enterrados en el mismo lugar donde posiblemente vivieron lleva a pensar en la relación entre muertos, vivos y ancestros. Respecto a esta triada Chapman (2000) propone que su relación está mediada a través de muchas formas materiales, siendo una de las principales los huesos. Es a través de ellos que se mantienen vivas las esencias de los muertos (Budja, 2010). De este modo, sus esencias fueron perpetuadas e incorporadas a la vida cotidiana del grupo, estando presentes en cada conversación, cada actividad y encuentro; se volvieron parte del espacio cotidiano, de la memoria comunal y de la identidad del grupo.

La cuestión de identidad también subyace en el entierro del infante en la urna cerámica. Muñoz Ovalle (2017), quien realiza su estudio en la población de un cementerio del valle de Azapa, Norte de Chile, habla de una identidad local posibilitada por una tecnología propia donde fueron parte los entierros en cestos-urnas. Si lo pensamos en el caso de esta comunidad, puede que este tipo particular de inhumación haya actuado como forjadora o reforzadora de algún tipo de identidad social o grupal a nivel familiar.

Como bien aclaran Murphy y Le Roy (2017), los niños muertos son manipulados dentro de un mundo adulto, y la evidencia de cómo fue la práctica de enterrarlos proporciona información sobre cómo los adultos llegaron a un acuerdo con las muertes prematuras de sus niños. En este caso, ¿Podría pensarse que el tratamiento completamente distinto, de inhumar al infante en una vasija de cerámica, se debiera a que su muerte significó una pérdida mucho más sentida y dolorosa para el grupo?, ¿Pudo este niño haber sido por algún motivo considerado vulnerable, por lo que se le brindó mayor protección al momento de enterrarlo? E incluso se puede ir más allá y pensar que tal vez fue inhumado a los pies de la mujer para ser protegido por ella.

Estos comportamientos son registrados en diversos sitios arqueológicos de las tierras bajas de Sudamérica (Mazza et al., 2016; Muñoz Ovalle, 2017) y en nuestro país en sitios guaraníes del extremo oriental de la Cuenca del Plata (Mazza et al., 2016). Los principales protagonistas de las inhumaciones en cestos-urnas, que fueron secundarias por notarse desarticulación, descarne y selección preferencial de determinados huesos -huesos largos y cráneo-, fueron los hombres adultos y en algunos casos subadultos. También se menciona que las urnas a veces eran encontradas tapadas por cuencos invertidos y acompañadas por grandes vasijas que incluían ajuares, pintura y restos de alimentos (Lothrop, 1932).

En el caso de Patagonia, no fueron habituales las inhumaciones en urnas, aun así, se reconoce una amplia variedad de modalidades inhumatorias, entre ellas las secundarias, donde hay manipulación postmortem de los cuerpos que posteriormente son enterrados junto a otros individuos (Berón y Luna, 2007; Martínez et al., 2006; Mazzia et al., 2004; Serna y Prates, 2012). En el norte Argentino, la frecuencia de entierros de subadultos en urnas aumenta desde momentos iniciales hasta el Período de Desarrollos Regionales (siglos IX a XV) (Baldini y Baffi, 2007). En Salta y Jujuy hay evidencias de párvulos en el interior de vasijas, presentando la particularidad de que no fueron urnas exclusivamente funerarias, sino que evidencian un uso previo en actividades cotidianas. Son de tipo ordinario, decoradas y en ocasiones presentan capas de hollín adheridas a la superficie externa lo que evidencian su uso en la cocina y fogones. El emplazamiento de los entierros era de modo directo, en espacios domésticos o cementerios cercanos a ellos, en ocasiones formando pequeños grupos y en menor frecuencia incluidas en cámaras con restos de adultos (Amuedo, 2015; Ortiz y Nieva, 2011; Seldes y Gheggi, 2016).

De este modo, el rito funerario del infante integró la materialidad cotidiana al espacio doméstico, donde vida y muerte guardaba una relación muy estrecha. Si bien no se cuenta con información en cuanto al tratamiento del niño/a dentro de la vasija o si la pieza tuvo vida útil en las tareas dentro del grupo, su disposición en una urna extiende (una vez más) lo doméstico a lo funerario.

Larrain y colaboradores (2017) y Amuedo (2015) hacen referencia a la constitución de subjetividades de las poblaciones del noroeste y relatan la mirada que tenían sobre los infantes y niños, a los que no se les aceptaba su identidad social hasta experimentar ciertos ritos o participar activamente en tareas dentro del grupo social. Esto derivaba en que si morían prematuramente no alcanzaban a interactuar socialmente en la comunidad, 
teniendo su muerte una trascendencia acotada en el grupo familiar. Ante esto, cabe pensar que este tipo de ritos podrían entrañar una búsqueda de integrarlo postmortem, a través de una protección especial. Por otro lado, en estas poblaciones eran habituales las ofrendas (Arnold, 1996) por lo que una posibilidad es estos entierros hayan estado relacionados a la búsqueda de protección del grupo doméstico o al pedido por la fertilidad de la tierra.

Las sociedades andinas compartían ontológicamente la subjetivación de personas y objetos, donde humanos y no humanos podían ser o no persona (Amuedo, 2015). Esta forma de percibir y entender el cuerpo humano y las relaciones entre humano y no-humano dista de nuestra visión moderna de la subjetividad y corporeidad. En el mundo andino, "el cuerpo se entrelaza y confunde con el mundo y otras entidades que habitan en él, por lo cual es permeable y no constituye una frontera" (Acuto et al., 2011, p. 25). Los individuos no son seres autónomos, dueños de sus propios cuerpos delimitados los cuales manipulan a voluntad en su relación con los demás seres, sino que son individuos interpelados por nudos de relaciones que incluyen otras personas, lugares y objetos (Le Breton, 2002). En el caso de las vasijas de cerámica fueron elementos que dentro de su historia en el ámbito doméstico pudieron ser transformados en sujetos activos. En este contexto, podría pensarse en la (re)utilización de urnas que hayan tenido vida útil dentro del grupo en el entierro de infantes, y así transmutar esa propiedad de persona a los niños.

Extrapolar estas creencias a las poblaciones que habitaron las sierras de Córdoba sería arriesgado, pero sí pueden ser consideradas para repensar la cuestión del luto experimentado por el grupo familiar y la trascendencia de las muertes tempranas de sus niños.

\section{Narrativa osteobiográfica}

"Ella detuvo su trajinar diario, ralentizado por los años que había transitado. En estos tiempos su tarea se reducía a la elaboración de materias primas que le proveían y a la producción de elementos tan valiosos para su comunidad. Era consciente de la destreza que había desarrollado y de la importancia de que estos saberes se reprodujeran y arraigaran en las jóvenes que compartían su tiempo y espacio.

...Espacio que seguiría perteneciéndole por presencia aún después de su muerte. Tiempo que sabía finito...

...Huellas que habían anidado en sus huesos le reclaman a gritos emprender un camino donde el tránsito fuera más liviano. Su espalda permanentemente adolorida, erguido sostén en sus años de juventud, le imponía comenzar a descender la mirada. También sus piernas, antes motores incansables, parecían haber adquirido entidad, al menos la suficiente para negarse a obedecer lo que tímida y espaciadamente ella les pedía.

Acomodó la preciada urdimbre entre sus dedos viejos y diestros y sus dientes desgastados pero aún solidarios y la imagen de su destino se presentó como surgida de ese tejido que mantenía en suspenso... Sería la guardiana de algún niño nacido o por nacer al que la vida se le escapara irremediablemente. Era la función inexorable y también la deseada. Lo acababa de dilucidar y ya lo deseaba.

Improvisó mentalmente su tumba. Un colchón terroso amortiguaría su humanidad y acunaría sus sueños ancestrales. Amorosamente acomodarían su rostro hacia el oeste -en su interior escuchaba fluir el agua del rio cercano- mientras que sus brazos rodearían sus piernas flexionadas. Y a sus pies... y a sus pies depositarían al pequeño. A modo de proyección del útero de su madre, que seguramente ni pudo estrenar el título de esta condición tan preciada, dispondrían de una vasija. En ella el niño nacido o por nacer. Ambos, integrados en un paisaje doméstico, transitado habitualmente".

Córdoba, 16 de marzo 2020

\section{Agradecimientos}

Este trabajo se desprende de la tesis de licenciatura de una de las autoras (PZ). Se enmarca en los proyectos FONCyT, PICT 2013-2028 y PICT 2015-3155, ambos dirigidos por la Dra. Mariana Fabra. Agradecemos a Rodrigo Nores por la información genética que fue utilizada en este trabajo, a Soledad Salega y Jorge Suby por sus aportes en relación a patologías óseas que fueron de mucha utilidad. A Marcos Salvatore por la realización del mapa. A Rodolfo Herrero, director del Museo Arqueológico Provincial Aníbal Montes, por facilitar el acceso a los restos analizados en este trabajo. Agradecemos al personal del Hospital Municipal Nuestra Señora de Nievas de Malagueño, en especial a María Soledad Oliva por la realización de las placas radiográficas. Finalmente, a las sugerencias realizadas por los evaluadores, las cuales mejoraron sensiblemente el trabajo.

\section{Referencias bibliográficas}

Acuto, F., Kergaravat, M. y Amuedo, C. (2011). Experiencia de la muerte y la representación de las personas en las prácticas funerarias del Valle Calchaquí Norte. Comechingonia. Revista de Arqueología, 14, 23-54.

Agarwal, S. y Glencross, B. (2010). Social Bioarchaeology. Nueva York: Wiley-Blackwell.

Agarwal, S. (2016). Bone morphologies and Histories: Life Course Approaches in Bioarchaeology.Yearbook of Physical Anthropology, 159, 130-149. 
Angel, J. (1946). Social Biology of Greek Culture Growth. American Anthropologist, 48(22), 493-533.

Amuedo, C. (2015). Las vasijas y su potencial como sujetos estabilizadores de seres incompletos: prácticas mortuorias de infantes durante el período tardío en el valle calchaquí norte. Estudios Atacameños. Arqueología y Antropología Surandinas, 50, 85-104.

Arias Toledo, B., Colantonio, S. y Galetto, L. (2007). Knowledge and use of edible and medicinal plants in two populations from the Chaco forest, Córdoba province, Argentina. Journal of Ethnobiology, 27, 218-232.

Arnold, D. (1996). Somos lo que comemos. En torno al incesto y el cultivo de la papa en el altiplano boliviano. En D. Arnold y J. Yapita (Eds.). Mamá Melliza y sus Crías. Ispall Mama Wawampi (pp. 195-222). La Paz: HisbolILCA.

Aufderheide, A. y Rodriguez Martin, C. (1998). The Cambridge Encyclopedia of Human Paleopathology. Cambridge: University Press.

Babot, M.P. (2003). Starch grain damage as an indicator of food processing. En: D.M. Hart and L.A. Wallis (Eds.). Phytolith and starch research in the Australian-PacificAsian regions: the state of the art (pp.69-81). Canberra: Pandanus Books for the Centre for Archaeological Research and the Department of Archaeological and Natural History, The Australian National University, Canberra.

Babot, M.P., Oliszewski, N. y Grau, A. (2007). Análisis de caracteres macroscópicos y microscópicos de Phaseolus vulgaris (Fabaceae, Faboideae) silvestres y cultivados del Noroeste argentino. Una aplicación en arqueobotánica. DARWINIANA, 45, 149-162.

Baldini, L. y Baffi, E. (2007). Aportación al estudio de prácticas mortuorias durante el Período de Desarrollos Regionales: Entierros en vasijas utilitarias del sector central del valle Calchaquí (Salta, Argentina). Revista Española de Antropología Americana, 37(1), 7-26.

Baker, B., Terhune, C. y Papalexandrou, A. (2012). The osteobiography of a woman medieval polis, Cyprus. En A. Stodder y A. Palkovich (Eds.). The Bioarcheology of Individuals (pp. 151-161). Florida: University Press.

Benvenuto, M.L., Honaine, M.F., Osterrieth, M.L. y Morel, E. (2015). Differentiation of globular phytoliths in Arecaceae and other monocotyledons: morphological description for paleobotanical application. Turkish Journal of Botany, 39 (2), 341-353.

Berón, M. y Baffi, E. (2003). Procesos de cambio cultural en los cazadores de la provincia de La Pampa, Argentina.
Intersecciones en Antropología, 4, 29-43.

Berón, M. y Luna, L. (2007). Modalidades de entierro en el sitio Chenque I. Diversidad y complejidad de los patrones mortuorios de los cazadores-recolectores pampeanos. En: C. Bayón, I. González, N. Flegenheimer, A. Pupio y M. Frère (Eds.). Arqueología en las Pampas (pp. 129-143). Buenos Aires: Sociedad Argentina de Antropología.

Blakely, R. (1977). Biocultural Adaptation in Prehistoric America, Southern Anthropological Society Proceedings. Atenas: The University of Georgia Press.

Brickley, M. e Ives, R. (2008). The Bioarchaoelogy of Metabolic Bone Disease. San Diego, CA: Academic Press.

Boutin, A. (2011). Craftin a Bioarchaeology of Personhood: Osteobiographical Narratives from Alalakh. En A. Baadsgaard, A. Boutin y J. Buikstra (Eds.). Breathing New Life into the Evidence of Death: Contemporary Approaches to Bioarchaeology (pp. 109-133). Santa Fe, New Mexico:School for Advanced Research Press.

Bozarth, S.R. (1987). Diagnostic opal phytoliths from rinds of selected Cucurbita species. American Antiquity, 52 (3), 607-615.

Budja, M. (2010). The archaeology of death: from 'social personae' to 'relational personhood'. Documenta Praehistorica, 37, 44-54

Buikstra, J. y Ubelaker, D. (1994). Standards for data Collection from Human Skeletal Remains: Proceedings of a Seminar at the Field Museum of Natural History. Fayetteville: Arkansas Archaeological Survey Press.

Campillo, D. (2001). Límites entre normalidad y anormalidad en Paleopatología. Actas del V Congreso Nacional de Paleopatología. Alcalá La Real.

Cantarella, V. (1999). Bones and Muscles: An Illustrated Anatomy. Nueva York: Wolf Fly Press.

Capparelli, A. y Lema, V. (2011). Recognition of postharvest processing of algarrobo (Prosopis spp.) as food from two sites of Northwestern Argentina: an ethnobotanical and experimental approach for desiccated macroremains. Archaeological and Anthropological Sciences, 3(1), 71-92.

Capasso, L. (1999). Brucellosis at Herculaneum (79 AD). International Journal of Osteoarchaeology, 9, 277-288.

Chapman, J. (2000). Fragmentation in Archaeology, People, places and broken objects in the prehistory of southeastern. Londres: Routledge.

Charles, R. (1893). The influence of function, as 
exemplified in the morphology of the lower extremity of the Panjabi.Journal of Anatomy and Physiology, 28, 1-18.

Clark, B. y Wilkie, L. (2006). The prism of self: gender and personhood. En Neslon, S. (Ed.). Handbook of Gender in Archaeology (pp. 333-364). Walnut Creek, CA: Alta Mira Press.

Coltrain, J. y Leavitt, S. (2002). Climate and Diet in Fremont Prehistory: Economic variability and abandonment of maize agriculture in the Great Salt Lake Basin. American Antiquity, 67(3), 453-485.

Cortella, A. y Pochettino, M. (1994). Starch grain analysis as a microscopic diagnostic feature in the identification of plant material. Economic Botany, 48(2), 171-181.

Dembo, A. e Imbelloni, J. (1938). Deformaciones intencionales del cuerpo humano. Buenos Aires: Humanior.

Douglas, M. (1996). Natural Symbols: Explorations in Cosmology. Londres: Routledge.

Estévez González, M. (2002). Marcadores de estrés y actividad en la población guanche de Tenerife. Tesis doctoral. Universidad de La Laguna, España.

Fabra, M. (2006). Informe Bioantropológico de Restos Óseos humanos. Sitio Banda Meridional del Lago. Museo de Antropología, Facultad de Filosofía y Humanidades. Universidad Nacional de Córdoba.

Fabra, M. y González, C. (2019). Oral health, diet and social change in populations of the region of central Argentina during late Holocene: Bioarchaeological and isotopic evidence. Latin American Antiquity, 30 (4), 818-835.

Fabra, M., Salega, S. y González, C. (2009). Comportamiento mortuorio en poblaciones prehispánicas de la región austral de las Sierras Pampeanas durante el Holoceno. Revista Arqueología, 15, 165-186.

Figueroa, G. y Dantas, M. (2006). Recolección, procesamiento y consumo de frutos silvestres en el noroeste semiárido argentino. Casos actuales con implicancias arqueológicas. La Zaranda de Ideas, 2, 35-50.

Flensborg, G. (2011). Dento-alveolar lesions and palaeodietaryinferencesfromthe Paso Alsina 1 site (Eastern Pampean-Patagoniantransition, Argentina). Revista Homo - Journal of Comparative Human Biology, 62, 335-350.

Ganot Rodríguez, J. y Peschard Fernández, A. (1997). Aztatlán: apuntes para la historia y arqueología de Durango. México: Gobierno del Estado de Durango,
Secretaría de Educación, Cultura y Deporte, Durango.

Gil, A., Tykot, R., Neme, G. y Shelnut, N. (2006). Maize on the frontier. Isotopic and macrobotanical data from CentralWestern Argentina. En J. Staller, R. Tykot y B. Benz (Eds.). Histories of Maize: Multidisciplinary Approaches to the Prehistory, Biogeography, Domestication, and Evolution of Maize (pp. 199-214). Nueva York: Academic Press.

Gilchrist, R. (2000). Archaeological biographies: Realizing human lifecycles, -courses, and -histories. World Archaeology, 31, 325-328.

Gilchrist, R. (2004). Archaeology and the Life Course: A Time and Place for Gender. En L. Meskell y R. Preucel (Eds.). A companion to Social Archaeology (pp.142-160). Oxford: Blackwell.

Glasgow, M. (1976). Brucellosis of the Spine. The British Journal of Surgery, 63, 283-288.

Gómez Otero, J. y Novellino, P. (2011). Diet, nutritional status and oral health in hunther-gatherers from the Central-Northern coast of Patagonia and the Chubut river lower valley, Argentina. International Journal of Osteoarchaeology, 21, 643-659.

González, C. y Fabra, M. (2018). Degaste dental y hábitos dietarios en poblaciones arqueológicas del centro de Argentina. Arqueología, 24(2), 133-159.

González-Reimers, E., Mas-Pascual, M., Arnay-de-laRosa, M., Velasco-Vázquez, J., Santolaria-Fernández, F. y Machado-Calvo, M. (2004). Noninvasive Estimation of Bone Mass in Ancient Vertebrae. American Journal of Physical Anthropology, 125, 121-131.

Guraieb, S. (2010). Bioarqueología de cazadoresrecolectores del Holoceno Tardío de la cuenca del lago Salitroso (Santa Cruz). Aspectos paleodemográficos y paleopatológicos. Vol. 2. Tesis de Doctorado en Arqueología de la Facultad de Filosofía y Letras. Universidad de Buenos Aires.

Henderson, C., Mariotti, V., Pany-Kucera, D., Villote, S. y Wilczak, C. (2015). The New 'Coimbra Method': A Biologically Appropiate Method for Recording Specific Features of Fibrocartilaginous Entheseal Changes. International Journal of Osteoarchaeology, 26 (5).

Henry, A. y Piperno, D. (2008). Using plant microfossils from dental calculus to recover human diet: A case study from Tell al-Raqa'i, Syria. Journal of Archaeological Science, 35, 1943-1950.

Henry, A., Hudson, H. F. y Piperno, D. (2009). Changes in starch grain morphologies from cooking. Journal of Archaeological Science, 36, 915-922. 
ICSN. (2011). The International Code for Starch Nomenclature. http://www.fossilfarm.org/ICSN/Code. html. Consultado el 20 de agosto 2020.

Madella, M., Alexandre, A., \& Ball, T. (2005). International code for phytolith nomenclature 1.0. Annals of botany, 96(2), 253-260.

Johnston, K. (2019). Opening Up the Family Tree: Promoting More Diverse and Inclusive Studies of Family, Kinship, and Relatedness in Bioarchaeology. En J. Buikstra (Ed.). Bioarchaeologists Speak Out,Bioarchaeology and Social Theory (pp. 201-230). Springer, Cham.

Korstanje, M.A. y Babot, M.P. (2007). A microfossil characterization from South Andean economic plants. En M. Madella, M.K. Jones y D. Zurro (Eds.). Places, People and Plants: Using Phytoliths in Archaeology and Paleoecology (Proceeding of the 4th International Meeting on Phytolith Research) (pp. 41-72). Cambridge: Oxbow Books.

Krogman, W. e Iscan, M. (1986). The human skeleton in forensic medicine. Springfield: Charles $\mathrm{C}$. Thomas Publisher, LTD.

Knudson, K. y Stojanowski, C. (2008). New Directions in Bioarchaeology: Recent Contributions to the Study of Human Social Identities. Journal Archaeological Research, 16(4), 397-432.

Laguens, A. y Bonnin, M. (2009). Sociedades indígenas de las Sierras Centrales. Arqueología de Córdoba y San Luis. Córdoba: Editorial Universidad Nacional de Córdoba.

Laneri, N. (2007). Performing death. Social analyses of funerary traditions in the ancient near east and Mediterranean. Chicago-Illonois: Oriental Institute of the Univ. of Chicago.

Larrain, A., Spano, R. y Grimoldi, M. (2017). Ollas como urnas, casas como tumbas: reflexiones en torno a las prácticas de entierro de infantes y niños pequeños en tiempos tempranos (Andalhuala Banda, sur de Yocavil). Comechingonia, Revista de Arqueología, 21(1), 39-70.

Larsen, C. (1987). Bioarchaeological Interpretation of Subsistance Economy and Behavior from Human Skeletal Remains. Advances in Archaeological Method and Theory, 10, 339-445.

Le Breton, D. (2002). Antropología del cuerpo y modernidad. Buenos Aires: Ediciones Nueva Visión.

López, L. (2015). Prácticas culinarias como medio para la reproducción social de los grupos prehispánicos de las sierras de Córdoba. En J. Salazar (Comp.). Condiciones de posibilidad de la reproducción social en sociedades prehispánicas y coloniales tempranas en las Sierras Pampeanas (República Argentina) (pp. 117-212). Córdoba: Centro de Estudios Históricos Prof. Carlos S. A. Segreti.

Lothrop, S. (1932). Indians of the Paraná Delta River. Annals of the New York Academy of Sciences, XXXIII, 77-232.

Loupias, L. y Fabra, M. (2019). Estudios de la tendencia secular en la talla de poblaciones humanas del centro de Argentina durante el Holoceno tardío. Jangwa Pana, $18(3), 1-23$

Lovejoy, C., Meindl, R., Mensforth, R. y Barton, T. (1985). Multifactorial determination of skeletal age at death: $A$ method and blind tests of its accuracy. American Journal of Physical Anthropology, 68, 1-14.

Luna, L. y Aranda, C. (2014). Trends in oral pathology of hunther-gatherers from Western Pampas, Argentina. Journal of Anthropological Science (The Anthropological Science of Nippon), 122(2), 55-67.

Mariotti, V., Facchini, F., y Belcastro, M. G. (2007). The study of entheses: Proposal of a standardised scoring method for twenty-three enthesesof the postcranial skeleton. Collegium Antropologicum, 31, 291-313.

Martin, D., Harrod, R., Ventura y Pérez, R. (2013). Bioarchaeology. An Integrated Approach to Working with Human Remains. Manuals in Archaeological Method, Theory and Technique. Nueva York: Springer Science.

Martínez, G., Bayala, P., Flensborg, G. y López, R. (2006). Análisis preliminar de los entierros humanos del sitio Paso Alsina 1 (partido de Patagones, provincia de Buenos Aires). Intersecciones en Antropología, 7, 95-108.

Mazza, B., Acosta, A. y Loponte, D. (2016). Nuevos datos para las inhumaciones en urnas de sitios arqueológicos guaraníes del extremo oriental de la Cuenca del Plata. Revista Chilena de Antropología, 34(2), 81-96.

Mazzia, N., Scabuzzo, C. y Guichón, R. (2004). Sobre cráneos, pelvis y otros huesos. Entierros humanos en el sitio El Guanaco. En: G. Martínez, M. Gutiérrez, R. Curtoni, M. Berón y P. Madrid (Eds.). Aproximaciones contemporáneas a la arqueología pampeana. Perspectivas teóricas, metodológicas, analíticas y casos de estudio (pp. 293-304). Olavarría: Facultad de Ciencias Sociales, Universidad del Centro de la Provincia de Buenos Aires.

Medina, M. y Pastor, S. (2006). Chacras dispersas. Una aproximación etnográfica y arqueológica al estudio de la agricultura prehispánica en la región serrana de Córdoba 
(Argentina). Comechingonia, Revista De Arqueología, 9 (1), 103-121.

Medina, M., López, L., y Berberián, E. (2009). Agricultura y recolección en el Tardío Prehispánico de las Sierras de Córdoba (Argentina): el registro arqueobotánico de $\mathrm{C}$. Pun.39. Arqueología, 15, 217-230.

Molnar, S. (1971). Human tooth wear, tooth function and cultural variability. American Journal of Physical Anthropology, 34(2), 175-189.

Moyad, M. (2003). Seminar Article. Osteoporosis: a rapid review of risk factors and screening methods. Urologic Oncology: Seminars and Original Investigations, 21, 375-379.

Munizaga, J. (1976). Deformación craneana intencional en América. Revista Chilena de Antropología, 6, 113-147.

Muñoz Ovalle, I. (2017). Espacios fúnebres, prácticas mortuorias y cronología en el cementerio Azapa-115: Aproximaciones en torno a la estructura social de los agricultores prehispánicos del período medio. Estudios Atacameños: arqueología y antropología surandinas, 54, 5-36.

Murphy, E. y Le Roy, M. (2017). Introduction: Archaeological Children, Death and Burial. En: E. Murphy y M. Le Roy (Eds.). Children, Death and Burial: Archaeological Discourses. Oxford y Filadelfia: Oxbow Books.

Musaubach, M. (2012). Potencialidad de estudios arqueobotánicos sobre tártaro dental de cazadores recolectores de la provincia de La Pampa, Argentina. Revista Argentina de Antropología Biológica, 105-113.

Nores, R., Fabra, M., Rena, V., Modesti, N. y Demarchi, D. (2014). Primer estudio de vínculo biológico en restos humanos arqueológicos del Mar de Ansenuza (Córdoba, Argentina). Libro de resúmenes XIII Congreso Asociación Latinoamericana de Antropología Biológica, Santiago de Chile, 15-18 de octubre, pp. 231.

Nores, R., Fabra, M. y Demarchi, D. (2011). Variación temporal y espacial en poblaciones prehispánicas de Córdoba. Análisis de ADN antiguo. Revista del Museo de Antropología, 4, 187-194.

O'Brien, T., Peters, L. y Hines, M. (2013). Artificial Cranial Deformation: Potential Implications for Affected Brain Function. Anthropology, 1(3), 107.

Okumura, M. (2014). Differences in types of artificial cranial deformation are related to differences in frequencies of cranial and oral health markers in pre-Columbian skulls from Peru. Boletim do Museu Paraense Emílio Goeldi. Ciências Humanas, 9 (1), 15-26.
Ortiz, G. y Nieva, L. (2011). Prácticas mortuorias en las poblaciones tempranas del valle del río San Francisco (prov. de Jujuy, Argentina). Comechingonia, Revista de Arqueología, 14, 55-73.

Ortner, D. (2003). Identification of Pathological Conditions in Human Skeletal Remains. Amsterdam:Academic Press.

Pastor, S. y Berberián, E. (2007). Arqueología del sector central de las Sierras de Córdoba (Argentina). Hacia una definición de los procesos sociales del periodo prehispánico tardío (900-1573). Intersecciones en Antropología, 8, 31-47.

Pate, D. (1994). Bone chemistry. Journal of Archaeological Method and Theory, 2, 161-209.

Piperno, D. (2006). Phytoliths. A Comprehensive Guide for Archaeologist and Paleoecologist. Estados Unidos: Altamira Press.

Riggs, B. y Melton, L. (1988). Osteoporosis. Etiology, diagnosis and management. New York: Raven Press.

Russo, G., Mendisco, F., Avena, S., Dejean, C. y Seldes, V. (2016). Pre-Hispanic Mortuary Practice in Quebrada de Humahuaca (North-Western Argentina): Genetic Relatedness among Individuals Buried in the Same Grave. Annals of Human Genetics, 80(4), 210-220.

Salega, S. y Fabra, M. (2013). Niveles de actividad física en poblaciones de las sierras y las llanuras de la provincia de Córdoba (Argentina) durante el Holoceno tardío. Revista Relaciones, tomo XXXVIII (2), 401-420.

Salega,S. (2017). Prácticas cotidianas, niveles de actividad física y modos de vida en poblaciones del sector austral de las sierras pampeanas durante el holoceno tardío -1a ed. -Córdoba:Universidad Nacional de Córdoba,https://ffyh. unc.edu.ar/editorial/wp-content/uploads/sites/5/2013/05/ EBOOK_SALEGA-1.pdf.

Seldes, V. y Gheggi, M. (2016). Prácticas Mortuorias en Quebrada de Humahuaca ca. 500-1550 AD. Revista Andes, 27. [Fecha de Consulta 1 de marzo de 2020]. ISSN: 0327-1676. Disponible en: https://www.redalyc. org/articulo.oa?id=127/12749260012.

Serna, A. y Prates, L. (2012). Bioarqueología y cronología el sitio Negro Muerto 2 (Noreste de Patagonia). Revista Magallania, 40(2), 233-245

Sofaer, J. (2006). Gender, bioarchaeology and human ontogeny. En: R. Gowland, y C. Knüdsel (Eds.). Social Archaeology of Funerary Remains (pp. 155-167). Oxford: Alden Press.

Stodder, A. y Palkovich, A. (2007). Individuals and 
populations: Complementary domains in bioarchaeology. American Journal of Physical Anthropology, Supplement 44, 226.

Stuart-Macadam, P. (1985). Porotic Hyperostosis: Representative of a Childhood Condition.American Journal of Physical Anthropology, 66, 391-398.

Stuart-Macadam, P. (1989). Porotic hyperostosis: relationship between orbital and vault lesions.American Journal of Physical Anthropology, 80, 187-193.

Suby, J., Costantino, S., Capiel, C., Lucarini, M. y Etchepare, E. (2012). Exploraciones de la densidad mineral ósea y osteopenia en poblaciones humanas antiguas de Patagonia austral.Intersecciones en Antropología, 14, 433-445.

Suby, J. (2014). Porotic hiperostosis and criba orbitalia in human remains from southern Patagonia. Anthropological Science, 122(2), 69-7.

Suchey, J. y Brooks, S. (1990). Skeletal age determination based on the pubis: a comparison of the Acsádi-Nemeskéri and Suchey-Brooks methods. Human Evolution, 5(3), 227-238.

Tiesler, V. (2012). Studying cranial vault modifications in ancient Mesoamerica. Journal of Anthropological
Sciences, 90, 1-26.

Todd, T. (1921). Age Changes in the Pubic Bone. III: The Pubis of the White Female. IV: The pubis of the female withe-negro hybrid. American Journal of Physical Anthropology, 4, 1-70.

Torres-Rouff, C. (2002). Cranial Vault Modification and Ethnicity in Middle Horizon San Pedro de Atacama, Chile. Current Anthropology, 43, 163-171.

Trotter, M. y Gleser, G. (1977). Estimation of stature from long limb bones of American Whites Negroes. American Journal Physical Anthropology, 47, 355-56.

Villote, S. y Prada Marcos, M. (2010). Marcadores ocupacionales en los hombres mesolíticos de la BrañaArintero.En J. Vidal Encinas y M. Pradas Marcos (Eds.). Los hombres mesolíticos de la cueva de la Braña-Arintero (Valdelugeros, León) (pp. 120-130). León.

Wiggenhauser, N. (2016). La variación cultural de las modificaciones artificiales del cráneo en Patagonia septentrional (4500-200 años AP): una perspectiva desde el modelo de herencia dual. Actas del XIX Congreso Nacional de Arqueología Argentina. Serie Monográfica y Didáctica, vol. 54. Facultad de Cs. Nat. e Instituto Miguel Lillo de la Univ. Nac. De Tucumán. 